\title{
Direitos Humanos e Fronteiras A Representação da Mulher na Mídia
}

\author{
Vera Lucia Spacil Raddatz \\ Doutorado em Comunicação e Informação. Professora do Programa de Pós-Graduação em Direito - Mestrado e Doutorado em \\ Direitos Humanos e do Curso de Comunicação Social da Unijuí. verar@unijui.edu.br

\section{Marjorie Barros Bock} \\ Graduada em Comunicação Social - Habilitação: Jornalismo (Universidade Regional do Noroeste do Estado do Rio Grande do Sul - \\ Unijuí). Possui experiência na área de Comunicação. Atua como membro do Núcleo de Educação e Informação em Direitos Humanos \\ - NEIDH, Projeto de Extensão junto ao PPGD - Curso de Mestrado em Direitos Humanos da Unijuí.marjbock@gmail.com
}

Este texto pretende discutir as fronteiras e os direitos humanos a partir da perspectiva de como a mulher é representada na mídia de fronteira e a que tipo de violência ela é exposta. A pesquisa é de caráter qualitativo e interdisciplinar, aproximando os estudos sobre a mídia de fronteira e as perspectivas de gênero e direitos humanos. Baseia-se no resultado de projeto de pesquisa e na coleta de dados sobre as formas de representação da mulher na mídia de fronteira, no período de agosto de 2017 a maio de 2018. A pesquisa constata a vulnerabilidade da mulher e a sua exposição às diversas formas de violência, tanto física quanto simbólica, fenômeno que se verifica em regiões de fronteira.

Palavras-chave: Fronteiras. Direitos humanos. Mulher. Violência. Mídia.

\section{BORDERS AND HUMAN RIGHTS: THE REPRESENTATION OF WOMAN IN THE MEDIA}

\section{ABSTRACT}

This text intends to discuss borders and human rights, from the perspective of how women are represented in the border media and to what kind of violence it is exposed. The research is qualitative and interdisciplinary in nature, bringing together studies on the frontier media and the perspectives of gender and human rights. It is based on the results of a research project and the collection of data on the forms of representation of women in the border media, from August 2017 to May 2018. The research notes the vulnerability of women and their exposure to diverse forms of violence, both physical and symbolic, a phenomenon that occurs in border regions.

Keywords: Borders. Human rights. Woman. Violence. Media.

\section{SUMÁRIO}

1 Introdução. 2 Fronteiras: um conceito que ultrapassa os limites físicos. 3 Direitos humanos e mídia: um olhar sobre a mulher. 4 Pelas fronteiras: quando a violência de gênero é contra a mulher. 5 Considerações finais. 6 Referências. 


\section{INTRODUÇÃO}

A palavra fronteira é substantivo feminino, bem como a palavra mulher. A fronteira é um território considerado periférico nas relações de poder. A mulher historicamente esteve relegada a uma posição secundária nas instâncias de poder. A representação da fronteira na mídia está associada a um espaço de violência, de contrabando e de tráfico, em detrimento da integração que existe entre nações vizinhas. A imagem da mulher na mídia de fronteira está frequentemente associada à violência ou à violação dos direitos de gênero.

Esta livre associação de ideias entre a fronteira e a mulher são resultado das investigações do projeto de pesquisa realizado no período de agosto de 2017 a maio de 2018, tendo como foco a mulher na mídia de fronteira, a partir da busca na Internet de palavras-chave: mulher, fronteira e direitos humanos, com o objetivo de compreender que tipos de notícias são veiculados sobre a mulher na mídia de fronteira.

A hipótese é de que essas formas de representação da mulher nas mídias estudadas estão associadas ao imaginário que se tem sobre a fronteira, relacionado a um aspecto evidente: a violência nestes lugares é tão presente quanto a violência específica contra a mulher. Há, portanto, uma vulnerabilidade tanto da mulher quanto da fronteira, do ponto de vista dos direitos humanos, pois ambos estão situados no invólucro da violência. Estudos sobre a fronteira e principalmente reportagens sobre a região fornecem elementos para a formação de uma visão pessimista desse território. E o modo como a mulher é exposta ali se enquadra como uma violência simbólica, pois se dá a partir das linguagens textual e imagética com que essas representações são construídas.

Os direitos humanos são o parâmetro ético para compreender a importância da igualdade de direitos, da justiça e da equidade, e tem como princípio básico o respeito a todas as pessoas, independentemente da nacionalidade, etnia, cor, sexo, religião, classe social, filosofia política ou idade. Esta perspectiva universalista respeita os diferentes e defende a dignidade humana, porque o mais importante é o respeito à vida e à liberdade. Desse modo, defende-se neste texto a importância de olhar mais atentamente para o papel dos meios de comunicação na fronteira e a forma como a imagem da mulher está sendo reproduzida, pois se a mídia cria representações e constrói realidades a partir da tessitura do cotidiano, então cabe observar como essa representação pode estar contribuindo para o fortalecimento de estereótipos sobre a mulher na sociedade ou para o desrespeito à equidade de gênero.

Como parte do resultado do projeto de pesquisa que analisa a mulher na mídia na relação com a fronteira, este texto apresenta um recorte sobre os dados divulgados pela Secretaria de Segurança Pública do Estado do Rio Grande do Sul e das notícias veiculadas sobre a mulher. Metodologicamente, a pesquisa, de caráter qualitativo, se dá a partir da inserção das palavras-chave mulher, mídia e fronteira, tendo como foco as principais notícias do mês de maio de 2018, considerando os municípios da fronteira gaúcha com maiores índices de violência contra a mulher.

O objetivo é compreender como os meios de comunicação estão exercendo a sua função de mediadores do processo do direito à informação, da cidadania e dos direitos humanos. Desse modo, espera-se identificar como está sendo construída a imagem da mulher por meio da instância midiática, mais precisamente o Jornalismo, principal fonte de veiculação de infor- 
mações na sociedade, hoje potencializado pelos sites e redes sociais. O método de pesquisa utilizado para a realização foi o dedutivo, procurando-se, a partir de premissas baseadas nos princípios dos direitos humanos, construir um raciocínio coerente a fim de elucidar a questão proposta.

Este texto constitui-se de três partes. Na primeira apresenta a fronteira, discutindo seu conceito a partir de um olhar que considera não apenas os limites físicos e geográficos, mas a questão contextual, histórica e cultura dessa região. Na segunda parte faz uma sucinta análise histórica dos direitos humanos e da sua importância na sociedade, relacionando-os à violência contra a mulher e ao papel da mídia na sociedade. Na terceira parte socializa a pesquisa realizada, fazendo a análise dos dados, discutindo-os à luz dos direitos humanos, da justiça e da equidade, especialmente no que diz respeito ao papel da mídia de fronteira e da forma como a mulher é nela representada.

\section{FRONTEIRAS: Um Conceito Que Ultrapassa os Limites Físicos}

Um olhar sobre a fronteira revela um território de ambiguidades, além de ser um espaço limítrofe que serve à demarcação geopolítica entre países. A fronteira fala por si mesma e pelo seu contexto, pois é impossível dizer o que ela é sem ultrapassá-la, seja como viajante ou como morador dessa região. O contexto fronteiriço move-se tanto pelo seu sentido das fronteiras físicas, pela visão de zona periférica, como pelas relações históricas e culturais que ali se estabelecem e onde também paira no ar um tanto de curiosidade pelo desconhecido, pelo vizinho próximo que fala outra língua e pelas constantes descobertas e trocas que se realizam todos os dias ao cruzar a rua, a ponte ou as águas deslizando em uma balsa.

O conceito de fronteira no seu aspecto simbólico diz respeito às representações coletivas dos homens que habitam esse território. O sentido e os valores que engrandecem uma divisa são estabelecidos pelas classificações, hierarquias e limites, dentro dos quais é possível apreciar o mundo e induzir as passagens de comunicação. Como cita Pesavento (2002, p. 36) no texto Além das Fronteiras, "[...] a fronteira é um limite sem limites, que aponta para um além". Inserida como um conceito de mobilidade, a fronteira encontra-se na história e se desenvolve através do tempo. Entendida como conceito narrado, a autora explica ainda que "a história é sempre um ser como, um discurso sobre um ter sido, na fronteira entre aquilo que teve lugar um dia e a representação que dele se constrói" (p. 37).

Compreender a fronteira também significa desprender-se da ideia de limite territorial puramente físico para adentrar em uma geografia em que o desenho foi construído pelo movimento humano, pela sua expressão, pelo jeito de ser e viver, sua linguagem, seus sonhos, conflitos e ambiguidades. É a fronteira cultural que fala mais forte do que as divisões estabelecidas politicamente e as pessoas que ali vivem sentem-se parte desse lugar.

Existem também conflitos e divergências. Cruzar a aduana não é um ato amistoso, apesar dos discursos de integração. O procedimento de apresentar documentação, abrir o porta-malas do carro, averiguar a mercadoria comprada, obedecer ao limite de 300 dólares para as compras, estar com o carro de acordo com as regras do país vizinho, ter a carta verde ao entrar na Argentina, por exemplo, preencher formulário de imigração na entrada e reapre- 
sentá-lo no retorno, encarar a fila longa, esperar uma vaga na balsa, são atos que carecem de maior simplicidade. Esse ritual burocrático consome tempo e paciência, principalmente de quem não é um turista, mas um cidadão da fronteira.

Iniciativas que pedem normas mais flexíveis para quem reside na região do Rio Grande do Sul com a Argentina e o Uruguai são reivindicações antigas que não se concretizam, apesar do Tratado do Mercosul, mas as barreiras não são construídas pelos cidadãos e sim pelas normas do Estado. Uma definição sobre a rotina de deslocamento dos fronteiriços entre um território e outro é apresentada pelo geógrafo Tito Carlos Machado de Oliveira (2015, p. 15):

\begin{abstract}
Cruzar as fronteiras algumas vezes ao ano é - ou pode ser - uma atitude de cosmopolitismo; mas cruzar a fronteira todos os dias, ou até várias vezes ao dia, é um ato de revolução. É necessário observar que as trocas corriqueiras no território fronteiriço são ditadas pela inclemência das necessidades orgânicas: comer, vestir, etc., e por preceitos intangíveis: desejo, amor, fazendo com que o ato de transgredir, violar, infringir, signifique para a população fronteiriça, na maioria das vezes, o imperativo ato de sobreviver e/ou resistir; caso fosse diferente, perderia seu significado. Esse deslocamento cotidiano de transeuntes faz nascerem e se materializarem circuitos íntimos com minúsculos sistemas de redes interativas subversoras aos interesses das nações.
\end{abstract}

As fronteiras são lugares de passagem, mas também de ancoragem. Carregam na sua marca as histórias e as vivências dos homens do lugar. O fato de uma cultura fronteiriça ser ambígua, mestiça e híbrida, mostra o quão rica em diversidade a fronteira pode ser. A pesquisadora da área de comunicação e fronteiras, Karla Maria Müller (2015), defende que existe uma cultura e uma identidade fronteiriça em que se destaca a pluralidade e o permanente movimento dos elementos que a constituem. Ao mesmo tempo que se misturam língua e costumes, também são evidenciados os elementos da identidade nacional. "O fronteiriço tem consciência de possuir uma identidade nacional que necessita ser reforçada a todo instante para garantir a diferença na relação com o vizinho" (MÜLLER, 2015, p. 132). E essas marcas de identidade, próprias dos fronteiriços, são expressas por meio das falas, dos gestos e das rotinas cotidianas.

Muito da identidade na fronteira é fruto das representações produzidas pela mídia da fronteira. A influência que os meios de comunicação exercem para além do seu redor sinaliza o ciclo de transformação a que o ser humano está condicionado no mundo contemporâneo. A pesquisadora Daniela Ota (2015, p. 181), ao se referir às fronteiras do centro-oeste brasileiro, afirma que "o homem fronteiriço tem uma mentalidade tendente à integração, pois para ele as noções de espaço e nacionalidade muitas vezes são tão abstratas quanto a ideia da existência de uma linha demarcatória que o separa do outro país".

Pesavento (2002, p. 36) também compreende a fronteira para além do aspecto geopolítico, reconhecendo que há uma referência imaginária: “[...] o conceito de fronteira trabalha, necessariamente, com princípios de reconhecimento que envolvem analogias, oposições e correspondências de igualdade, em um jogo permanente de interpenetração e conexões variadas". Os elementos peculiares que compõem esse limite integram um espaço de complexidade no qual as identidades são múltiplas. Aqueles que nela habitam estão sempre em busca de novas compatibilidades, como observa Canclini (1997, p. 324), pois "vivem no meio, na 
fenda entre dois mundos, já que são os que não fomos porque não mudamos, os que ainda não chegamos ou não sabemos aonde chegar, decidem assumir todas as identidades possíveis".

No Rio Grande do Sul são 12 as cidades que fazem fronteira com o Uruguai e/ou a Argentina: Aceguá, Barra do Quaraí, Chuí, Itaqui, Jaguarão, Porto Lucena, Porto Xavier, Quaraí, Santa Vitória do Palmar, Santana do Livramento, São Borja e Uruguaiana.

Aceguá, com 4.394 mil habitantes, está localizada no extremo Sul do Brasil e limita-se com a cidade homônima Aceguá no Uruguai, separada apenas por uma rua e um canteiro central. Conforme o site da prefeitura de Aceguá, "esta irmandade entre os dois países tem mais que a relação geográfica" (on-line), o que é possível observar pelo sotaque e pela linguagem de seus habitantes - o portunhol - ou seja, a mistura do português e do espanhol, resultado da convivência entre os povos das duas nacionalidades.

À margem dos Rios Quaraí e Uruguai situa-se o município de Barra do Quaraí, que faz fronteira com dois importantes países platinos, Uruguai e Argentina. No último censo, em 2010, a cidade tinha uma população de 4.012 habitantes. É a única cidade de tríplice fronteira do Estado e é o ponto mais a oeste do RS. O município conta com essa fronteira fluvial onde está localizada a ponte internacional Bella Unión, que conecta a cidade à rede rodoviária brasileira por meio da BR 472, ligando os países e possibilitando uma forte atividade comercial, devido ao câmbio favorável para a fronteira.

Ao extremo sul do Brasil está o município de Chuí, que com 5.917 habitantes é a cidade mais meridional do país, fazendo fronteira conurbada com a cidade do Chuy, no Uruguai. As cidades são separadas apenas por uma longa avenida com um canteiro central. De acordo com o censo demográfico do Brasil de 2010, Chuí é a cidade brasileira com a maior concentração de estrangeiros. Há um grande número de árabes palestinos residindo na cidade por conta do comércio.

A cidade de Itaqui está situada às margens do Rio Uruguai, divisa entre Brasil e Argentina, sendo esse um dos atrativos para os turistas que a visitam. Localizada na parte sudoeste do Rio Grande do Sul, Itaqui estima sua população em 38.159 habitantes no último censo realizado pelo IBGE em 2010.

No extremo sul do país está Jaguarão, que faz fronteira com o Uruguai. A cidade, com quase 28 mil habitantes, é ponto de chegada para a vizinha uruguaia, Rio Branco, onde na última década instalaram-se muitos freeshops, razão da grande movimentação de brasileiros que vão até lá em busca de artigos de marca. Logo cedo eles cruzam a ponte internacional Barão do Mauá, erguida pelo governo uruguaio entre 1927 e 1930 sobre o Rio Jaguarão. A ponte é um Monumento Histórico Nacional uruguaio desde 1977 e foi tombada pelo Iphan em 2011, para em 2015 receber também o Certificado de Patrimônio Cultural pelo Mercosul Cultural (IPHAN, 2015).

Com uma população de 5.413 pessoas, Porto Lucena nasceu da constituição de um núcleo populacional em razão das atividades comerciais que aconteciam por conta de sua localização às margens do Rio Uruguai. O município tem uma leve inclinação no sentido Rio Uruguai - leste/oeste - e é vizinho de outro município fronteiriço: Porto Xavier. Um dos recentes 
municípios do Alto Uruguai é Porto Xavier, com 10.558 habitantes, banhado pelas águas do Rio Uruguai, faz fronteira fluvial com a Argentina, com o transporte de cargas e pessoas ocorrendo pelo Porto Internacional de Porto Xavier.

Com uma população estimada em quase 24 mil habitantes, Quaraí é um dos maiores municípios gaúchos em área territorial, com 3.147,631 km² e faz parte da Região da Fronteira Oeste do Rio Grande do Sul. Quaraí está localizada na fronteira com o Uruguai, fazendo divisa com a cidade de Artigas. Ambas as cidades comunicam-se pela Ponte Internacional da Concórdia, construída em 1968 sobre o Rio Quaraí, considerada a ponte com a curva mais larga da América do Sul.

Com mais de 30 mil habitantes, Santa Vitória do Palmar localiza-se no extremo sul do Brasil, fazendo fronteira com o Uruguai. Juntamente com a cidade de Rio Grande, abriga a mais importante estação ecológica do Rio Grande do Sul e uma das mais importantes do país, a Estação Ecológica do Taim. E, com o município do Chuí, possui o maior complexo para geração de energia eólica da América Latina, o Complexo Eólico Campos Neutrais.

$\mathrm{Na}$ fronteira do Brasil com o Uruguai também está Santana do Livramento, um dos municípios mais antigos e o segundo maior em extensão territorial do Rio Grande do Sul. Com 82.464 habitantes segundo o último censo do IBGE de 2010, a cidade faz divisa seca com Rivera, no Uruguai, totalizando mais de cem quilômetros de faixa de fronteira seca com este país. Situada na chamada fronteira oeste do Estado, juntamente com outros municípios, integra a região fisiográfica da Campanha, que perfaz uma área total de $62.681 \mathrm{~km}^{2}$ o que representa aproximadamente $22 \%$ da área territorial do Rio Grande do Sul.

Fundada pelos padres jesuítas espanhóis, São Borja tem a civilização mais antiga do Rio Grande do Sul. Com uma população estimada em 62 mil habitantes, São Borja está localizada na fronteira oeste do Estado e seu território é banhado pelo Rio Uruguai, fronteira natural com a cidade de Santo Tomé, localizada na Província de Corrientes, na Argentina. É declarada, por lei estadual, a Terra dos Presidentes, por ser a cidade natal de dois ex-presidentes do Brasil: Getúlio Vargas e João Goulart.

Localizada às margens do Rio Uruguai na Fronteira Oeste do Rio Grande do Sul, Uruguaiana é a segunda maior cidade fronteiriça brasileira (a primeira é Foz do Iguaçu, fronteira com o Paraguai). Com uma população de 125.435 habitantes a cidade possui, por conta de sua localização estratégica, o Porto Rodoferroviário de Uruguaiana (Porto Seco). O Porto está situado na BR-290 e é, atualmente, o maior do gênero na América Latina, e o terceiro maior do mundo. Ele faz ligação com o centro do país por via rodoviária, por meio da BR/472, que percorre a Fronteira Oeste do Brasil a partir do Rio Grande do Sul.

\section{DIREITOS HUMANOS E MÍDIA: Um Olhar Sobre a Mulher}

Os direitos humanos compreendem a dignidade humana acima de qualquer outro valor. A dignidade é inerente à pessoa, independentemente de qualquer qualidade social, moral ou biológica e por isso, todos os seres humanos precisam ser tratados com dignidade, protegidos, portanto, de humilhações. A dignidade, desse ponto de vista, é da natureza humana e 
não precisaria de nenhuma lei para garanti-la, entretanto as leis fazem-se necessárias porque há desrespeito aos direitos humanos individuais e coletivos em todas as sociedades, mesmo naquelas que vivem um Estado Democrático de Direito.

Todos os dias se ouve defesas em prol dos direitos humanos, mas há também manifestações equivocadas sobre o real papel dos direitos humanos, relacionando-os à proteção apenas dos condenados ou das minorias, ou dos diferentes e não aceitos como iguais no conjunto da sociedade. É preciso frisar que os direitos humanos são para todos, mas o conjunto de problemas que afetam a humanidade do nosso tempo é tão grande e complexo que algumas desumanidades acabam sendo aceitas pelo senso comum como normais.

Entre os maiores problemas atuais estão as desigualdades sociais e econômicas, os conflitos político-religiosos, que produzem os horrores da guerra, entre outras consequências, e a falta de reconhecimento dos diferentes. Na esteira destes vem uma série de outras incontáveis adversidades que em sua essência desrespeitam os direitos das pessoas.

Três documentos históricos são os balizadores das preocupações com a defesa dos direitos humanos e foram fundamentais para esta luta: a Declaração de Direitos da Virgínia, em 1776, a Declaração de Direitos do Homem e do Cidadão, de 1789, e a Declaração Universal dos Direitos Humanos, de 1948. Conforme Bedin (2002, p. 187), o primeiro documento representa o "bom povo da Virgínia, reunidos em plena e livre convenção; direitos que pertencem a eles e à sua posteridade, com base e fundamento de governo". Em seu artigo 10, a Declaração defende que "todos os homens são, por natureza, igualmente livres e independentes e têm direitos inerentes [...]".

O segundo documento reforça também no artigo 10 a mesma concepção de igualdade de direitos: "os homens nascem e permanecem livres e iguais em direitos. As distinções sociais não podem fundar-se em nada mais do que na utilidade comum" (BEDIN, 2002, p. 191).

O terceiro documento, fruto da Assembleia Geral da ONU - Organização das Nações Unidas - proclama que o seu conteúdo é o "ideal comum a ser atingido por todos os povos e todas as nações" e que toda a sociedade está convocada a fazer a sua parte para promover o respeito aos direitos e liberdades. A Declaração, em consonância com os documentos já citados, assim determina em seu artigo 10: "Todos os homens nascem livres e iguais em dignidade e direitos. São dotados de razão e consciência e devem agir em relação uns aos outros com espírito de fraternidade". O conjunto dos artigos da Declaração fundamenta-se na luta contra a opressão e a discriminação, e defende a igualdade e a dignidade, reconhecendo os direitos básicos e as liberdades fundamentais do homem.

Os direitos humanos baseiam-se na liberdade de pensamento e expressão e na igualdade perante a lei. São também os que garantem a igualdade social e econômica e as condições mínimas para viver em sociedade, assegurando aos cidadãos uma vida digna com alimentação, saúde, moradia e educação. Os direitos fundamentais são aqueles que "não são suspensos em nenhuma circunstância, nem negados para determinada categoria de pessoas (...) são bem poucos os direitos considerados fundamentais que não entram em concorrência com outros direitos também considerados fundamentais" (BOBBIO, 1992, p. 20).De acordo com Bobbio (1992), a Declaração Universal dos Direitos Humanos, embora tenha sido escrita no passado, preconiza uma ideia do que se entende como o ideal de futuro para a sociedade em termos de proteção e reconhecimento dos direitos fundamentais e humanos, mostrando-se 
imprescindíveis, portanto, nos documentos de regulação das sociedades democráticas. $\mathrm{Na}$ Constituição brasileira a "prevalência dos direitos humanos" encontra-se descrita no Artigo 40, Inciso II (BRASIL, 1988, p. 5).

O desenvolvimento tecnológico da sociedade em rede propiciou que as ideias circulassem de forma ampla pelo mundo, o que provocou uma maior abertura para o conhecimento e as trocas culturais, mesmo entre cidadãos de diferentes partes do mundo que falam línguas diferentes. A globalização da economia abriu os mercados e aumentou o fluxo contínuo das pessoas entre os continentes, tanto para estudar, fazer turismo, trabalhar ou estabelecer novos negócios. O aumento da população também forçou migrações em busca de novos horizontes e o avanço das comunicações diminuiu as distâncias e quebrou obstáculos nas fronteiras físicas e geográficas.

Todas essas condições são férteis para que se desenvolva a internacionalização dos direitos humanos, que se inicia em 1948, com a Declaração Universal dos Direitos Humanos e soma-se ao surgimento de um conjunto de novos direitos. Bedin e Grando (2015, p. 98) destacam que as Conferências de Teerã (1968) e de Viena (1993) interferiram na solidificação dos direitos humanos, abrindo perspectivas para um diálogo mundial dos direitos humanos, reafirmando-se sua universalidade e indivisibilidade.

Os pesquisadores afirmam que "a partir do novo cenário existente no período pós-Segunda Guerra Mundial, a sociedade mundial necessita de uma nova adequação para tratar dos direitos humanos, com a finalidade de sempre proteger-se cada vez mais as vítimas e dar maior efetividade aos direitos" (BEDIN; GRANDO, 2015, p. 98), mas são as duas Conferências que "representam importantes ferramentas para a verificação acerca de como estão sendo tratados os direitos humanos no cenário mundial, bem como quais medidas vêm sendo tomadas no sentido de sua efetivação" (2015, p. 98).

A mídia se estiver associada ao seu papel social e ao caráter social da comunicação tem compromisso com a democracia e com os direitos humanos. Deste conjunto de informações resulta algum tipo de conhecimento não formal que contribui para a vida dos cidadãos. $A$ mídia exerce papel importante na formação de opiniões e pontos de vista na sociedade, portanto também realiza educação, mesmo que no âmbito informal, e agrega algum tipo de valor à bagagem que a escola, a universidade, os grupos sociais e a família vêm produzindo, cada um a seu modo, para o desenvolvimento dos indivíduos. É, portanto, o conjunto destes elementos que influencia a formação e os argumentos dos cidadãos.

Entende-se, então, que a mídia tradicional e as novas mídias funcionam como uma espécie de espaço público, e poderia se apropriar desta condição para contribuir para a discussão de pautas relacionadas aos direitos humanos, que de fato sejam significativas para o exercício da cidadania. Hannah Arendt (1958) em sua obra A Condição Humana apontou o espaço público como um lugar de diálogo, onde essencialmente o cidadão alcançaria a liberdade. Entenda-se esta liberdade como a possibilidade de participar ativamente na vida pública. Arendt entendia a comunicação como um pilar desse espaço público. Sobre este aspecto, Lafer (2003, p. 35), analisa que "restaurar, recuperar, resgatar o espaço público que permite, pela liberdade e pela comunicação, o agir conjunto, e com ele a geração do poder, é o grande tema unificador da reflexão de Hannah Arendt". 
A mídia, portanto, a partir de uma sintonia com a internacionalização do Direito e as políticas de universalização dos direitos humanos, reúne propriedades razoáveis para cumprir a função de informar os cidadãos sobre os seus direitos, mas também o dever de fiscalizar e denunciar a prática da violação aos direitos humanos em casos de exploração de menores, tráfico de pessoas, trabalho escravo, discriminação e violência de gênero, entre outros crimes que atentem contra os direitos humanos e a cidadania universal.

As tecnologias criaram mecanismos para que os receptores sejam cada vez mais ativos e participativos, influindo nas rotinas de produção midiática, que precisa se manter constantemente mais atenta não só à agenda factual, mas a grandes temas de interesse da humanidade. Os profissionais da mídia, diante desse quadro precisam se colocar como aptos a investigar e investir na produção de conteúdos, tendo em vista a proteção aos direitos humanos. Assim, estarão também em sintonia com os rumos da História e os anseios do público. Desse ponto de vista, a mídia pode ser agente articulador de políticas capazes de intervir na sociedade.

Nas últimas décadas as mulheres têm conquistado cada vez mais espaços e posições importantes na sociedade. Essa ascensão, entretanto, é recente e não apaga um passado no qual a mulher possuía um papel invisível na História. O renascimento do feminismo nos anos 70 garantiu direitos legais às mulheres, o acesso à educação superior e abriu caminho para entrarem cada vez mais para o mundo dos negócios, derrubando a mistificação do sexo frágil de uma mulher que tomava conta apenas da casa, lugar onde apenas tinham reconhecimento por serem esposa ou mães.

A figura feminina foi construída culturalmente a partir de uma violência simbólica de gênero que diz respeito aos motivos pelos quais essas mulheres foram intimidadas e colocadas quase sempre num estado de inferioridade. Por conta de uma sociedade predominantemente patriarcal, as representações sociais de gênero são caracterizadas por uma figura que dissemina uma representação constrangedora da mulher.

Para Jodelet (2002, p. 22), as representações sociais são "uma forma de conhecimento socialmente elaborado e compartilhado, com um objetivo prático, e que contribui para a construção de uma realidade comum a um conjunto social." Assim, nenhum discurso sobre qualquer coisa foge à lógica da construção de uma realidade determinada a partir das representações que se tem sobre ela. É uma construção em nível de discurso e todo o discurso é concebido a partir de uma cultura de comportamentos, experiências e saberes, portanto uma construção social.Bourdieu (2014), quando trata da divisão entre os sexos, explica que parece existir uma ordem natural estabelecida, como se isso estivesse "na ordem das coisas" e que esse processo estaria institucionalizado em todos os lugares em um "estado objetivado nas coisas (na casa, por exemplo, cujas partes são todas "sexuadas"), em todo o mundo social e, em estado incorporado, nos corpos e nos habitus dos agentes, funcionando como sistemas de esquemas de percepção, de pensamento e de ação" (p. 21).

Como o corpo é o primeiro lugar de visibilidade, a sociedade encarou a mulher a partir de seus traços físicos, como seu corpo, e bastando-a por sua reprodução. Por conta da menstruação, da gravidez e do parto, as mulheres foram destinadas ao silêncio e à invisibilidade, fazendo com que sua luta não fosse totalmente efetiva. Nesse sentido, o conceito de gênero começa a ser utilizado para denunciar esse tipo de violência que a mulher sofre ao longo dos 
anos. Colling (2014, p. 15) afirma que examinar a história a partir do gênero é questionar os modelos existentes, "tornando visível o androcentrismo do discurso científico e histórico tradicional, condicionando-se assim a produção global da história".

A importância de utilizar esse conceito é a de indicar que a condição das mulheres não é mais restrita à sua natureza, comprovando que as características físicas não inferiorizam ou magnificam. $O$ gênero diferencia socialmente as pessoas, levando em consideração os padrões histórico-culturais atribuídos para os homens e mulheres. A partir desse discurso é necessário descontruir um estereótipo produzido ao longo da história. Scott (1998, p. 15) define gênero como o "discurso da diferença dos sexos. Ele não se relaciona simplesmente às idéias, mas também às instituições, às estruturas, as práticas cotidianas como aos rituais, e tudo o que constitui as relações sociais". A historiadora ressalta a importância do discurso como instrumento de entrada na ordem do mundo, que embora não reflita a realidade biológica primeira, é o que constrói o sentido desta realidade. "A diferença sexual não é causa originária da qual a organização social poderia derivar; ela é, antes, uma estrutura social móvel que deve ser analisada nos seus diferentes contextos históricos" (SCOTT, 1998, p. 15).

O discurso masculino sobre o corpo da mulher naturaliza a feminilidade a partir da capacidade de reprodução, expressando que a condição feminina se dá apenas pela maternidade. Essa fala confirma a desigualdade hierárquica vivida na sociedade. Pierre Bourdieu explica que a definição social dos órgãos sexuais não é apenas um registro de propriedades naturais, mas "produto de uma construção efetuada à custa de uma série de escolhas orientadas, ou melhor, através da acentuação de certas diferenças, ou do obscurecimento de certas semeIhanças" (BOURDIEU, 2014, p. 29).

$\mathrm{Na}$ fronteira, esse contraste social é ainda mais acentuado por conta da identidade cultural dessa região, composta por diferentes elementos que caracterizam os povos que nela habitam. Os modos de vida, as línguas presentes e os valores fazem com que estudar a violência de gênero fronteiriça seja algo complexo e delicado. A existência dessa identidade, causada por uma interação social entre as diferentes culturas, efetiva um conjunto de costumes e valores de uma população que se reinventa para habitar uma área.

Quando se trata de violência e segurança na faixa de fronteira em geral a questão é apresentada dentro de uma relação com o tráfico de drogas e o contrabando, principais crimes cometidos nesse local. Embora as situações de violência contra a mulher não sejam específicas da área fronteiriça, elas ganham maior proporção por receberem pouca atenção devido à prioridade de outros assuntos pelos órgãos de segurança dessa região.

\section{PELAS FRONTEIRAS: Quando A Violência de Gênero é Contra a Mulher}

A pesquisa da qual resultou a reflexão deste texto foi realizada de agosto de 2017 a maio de 2018, e aqui faz um recorte territorial em relação às cidades do Rio Grande do Sul que fazem fronteira com a Argentina e o Uruguai. A fundamentação da pesquisa está baseada nos direitos humanos, tendo como perspectiva um olhar universalista sobre as questões relacionadas ao ser humano, reconhecendo que mesmo em culturas distintas e com diferenças culturais bastante evidentes, deve predominar o reconhecimento dessas diferenças, a equidade de direitos e a justiça. Os direitos humanos são para todos e todas, preservando em primeiro lugar a dignidade de cada ser humano. Desse ponto de vista, analisar a representação 
da mulher em determinados espaços ou culturas é um exercício de observação de como a sociedade ainda precisa evoluir na concepção da igualdade de direitos, eliminação do preconceito e discriminação e, principalmente, no combate à violência e na realização de projetos em educação para os direitos humanos. E a fronteira é um destes lugares em que é necessário investir em propostas direcionadas para tal fim.

A pesquisa é de caráter qualitativo e se utiliza do método hipotético dedutivo. O propósito deste texto é refletir sobre os direitos humanos com foco na mulher e na forma como ela é representada na mídia de fronteira. O recorte de pesquisa realizado para este artigo apresenta os dados sobre a violência cometida contra a mulher nas 12 cidades do Rio Grande do Sul que se situam na região de fronteira imediata com a Argentina e o Uruguai. Salienta-se que estes dados são os que são conhecidos tecnicamente, pois muitos casos de violência cometida contra a mulher nem são registrados, muitas vezes pela situação de vulnerabilidade familiar ou social em que se encontram as vítimas. Os dados foram divulgados pela Secretaria de Segurança Pública (SSP) - Departamento de Integração, Planejamento e Política de Segurança - Observatório Estadual de Segurança Pública (2018, on-line). Essa coleta realizada sobre as 12 cidades que fazem fronteira com o Uruguai e/ou a Argentina revelam a necessidade de as instâncias competentes encontrarem mecanismos que atuem dentro dos órgãos de segurança pública para combater a evidência de violência de gênero contra a mulher (Quadro 1).

Quadro 1 - Violência contra a mulher na fronteira gaúcha

\begin{tabular}{|l|c|c|c|c|c|}
\hline Cidade & 2017 & $\begin{array}{c}\text { Total (des- } \\
\text { de 2012) }\end{array}$ & \%(vítimas/total) & $\begin{array}{c}\text { População de } \\
\text { mulheres }\end{array}$ & $\begin{array}{c}\text { Taxa de mulheres } \\
\text { vítimas/10.000 } \\
\text { hab. 2016 }\end{array}$ \\
\hline ACEGUÁ & 4 & 27 & 0,01 & 2.091 & 28,69 \\
\hline BARRA DO QUARAÍ & 16 & 53 & 0,02 & 1.485 & 74,07 \\
\hline CHUÍ & 17 & 136 & 0,05 & 2.996 & 93,46 \\
\hline ITAQUI & 110 & 817 & 0,32 & 19.125 & 76,34 \\
\hline JAGUARÃO & 80 & 412 & 0,16 & 14.343 & 36,95 \\
\hline PORTO LUCENA & 8 & 78 & 0,03 & 2.715 & 29,47 \\
\hline PORTO XAVIER & 45 & 310 & 0,12 & 5.258 & 98,90 \\
\hline QUARAÍ & 54 & 405 & 0,16 & 11.793 & 61,90 \\
\hline SANTA VITÓRIA DO PALMAR & 147 & 953 & 0,38 & 15.521 & 106,95 \\
\hline SANTANA DO LIVRAMENTO & 337 & 1.767 & 0,70 & 43.088 & 70,55 \\
\hline SÃO BORJA & 232 & 1.593 & 0,63 & 31.423 & 76,38 \\
\hline URUGUAIANA & 424 & 2.926 & 1,15 & 64.426 & 73,57 \\
\hline
\end{tabular}

Fonte: Elaboração reeditada a partir dos dados publicados pela Secretaria de Segurança Pública (SSP)

- Departamento de Integração, Planejamento e Política de Segurança - Observatório Estadual de Segurança Pública (2018 - on-line). 
O relatório disponível no site da Secretaria de Segurança Pública (SSP) apresenta a partir de quadros o monitoramento dos indicadores de violência contra mulheres e meninas ocorrida em cidades gaúchas. Esses dados são de delitos que se enquadram na Lei Maria da Penha, lei no 11.340, de 7 de agosto de 2006.

O recorte temporal realizado para melhor compreender a pesquisa sobre a representatividade da mulher na mídia de fronteira separou apenas as informações das cidades do Rio Grande do Sul que fazem fronteira com o Uruguai e com a Argentina.

Por meio do comparativo é possível observar que a Fronteira Sul, com as cidades de Chuí, Santa Vitória do Palmar e Jaguarão, apresenta um índice maior de violência de gênero do que a Fronteira Oeste. A média apontada desde 2012 em Chuí é de 22 casos por ano, o que, com uma população de mulheres relativamente menor que nas outras cidades, revela uma taxa alta de vítimas. Santa Vitória do Palmar indica a maior taxa de mulheres vítimas de violência - 106,95 por 10 mil habitantes em 2016 - com 166 casos, dado obtido da tabela completa disponível no site da Secretaria de Segurança Pública (SSP). Com a cidade de Jaguarão a Fronteira Sul totaliza 1.501 casos relatados pela Secretaria desde 2012, revelando a necessidade de uma política que diminua os crimes de violência contra a mulher.

Uruguaiana é uma das situações mais preocupantes em relação aos dados divulgados nesse quadro. A maior cidade da região oeste e da fronteira do Rio Grande do Sul em população revela quase 3 mil ocorrências em seis anos, uma média de 488 casos por ano. 0 índice reflete a violação que essa minoria social sofre pela falta de mecanismos que desenvolvam políticas públicas a fim de enfrentar esse tipo de violência, que tem menor visibilidade que outros tipos de crime na fronteira.

A condição fronteiriça impõe desafios específicos para resolver os acontecimentos próprios da violência de gênero. Por se tratar de uma área em que os problemas com a criminalidade e a segurança são postos em evidência para serem solucionados com urgência, casos de violência contra a mulher, por exemplo, recebem uma atenção secundária e levam mais tempo para serem resolvidos, o que revela que existe uma carência de projetos destinados a esse fim.

Em uma sociedade na qual os discursos são predominantemente machistas, buscar por dados, entrevistas e mais informações que visam ao reconhecimento da mão de obra feminina é um grande desafio. A pesquisa desenvolvida procura compreender o papel dos meios de comunicação como mediadores do processo do direito à informação, da cidadania e direitos humanos, com vistas a entender como a mulher é representada na mídia de fronteira a partir da análise da relação entre as representações da mulher na mídia de fronteira e os direitos humanos.

Para tanto, durante o período de agosto de 2017 a maio de 2018 realizou-se a pesquisa de campo na Internet por meio do mapeamento de portais de notícias da fronteira e publicações em mecanismos de busca sobre as mulheres. A partir disso foi formado um acervo e arquivo do material já coletado, a fim de analisar os dados obtidos durante a pesquisa sobre a maneira como a mulher é representada nas mídias, principalmente a de fronteira. 
Ao analisar os meios de comunicação e as formas de produção da comunicação, pode-se afirmar que a mídia atua como mediadora em um processo de dar visibilidade às informações. A abertura da mídia aos movimentos feministas propicia maior visibilidade à discussão sobre o tema do protagonismo da mulher, entretanto o empoderamento feminino ainda é tratado a partir de um debate pouco explorado dentro de nossa sociedade. Na metade dos anos 90, quando a Internet chegou ao Brasil, o Jornalismo passou por uma grande mudança em seu processo de comunicação e na maneira como as informações são divulgadas. $O$ surgimento de variados canais de informações on-line promove um novo modelo do modo de distribuir as notícias. O Jornalismo on-line, presente nas plataformas digitais, oferece ao público a vantagem de garantir a facilidade de acesso à informação com atualizações constantes e divulgações mais rápidas que em outras mídias tradicionais.

A mídia fronteiriça apresenta um caráter do Jornalismo on-line estático; os principais veículos de comunicação deixam de lado a produção voltada somente para o digital e apenas copiando as notícias já divulgadas nos jornais físicos. Como analisa Müller (2015, p. 128):

Mesmo lançando mão de novos recursos, no entanto, percebe-se que a mídia local fronteiriça ainda engatinha no que diz respeito ao emprego das possibilidades que a Web oferece. Em relação à agilidade da Internet, os meios de comunicação deixam a desejar. As trocas entre leitor/internauta e produtores da informação são pequenas. De modo geral, os portais, sites e blogs que analisamos são bastante estáticos. Muitos deles representam mais um repositório de dados, composto por edições anteriores dos periódicos, do que um canal de atualização constante que pode ser buscado pelos interessados para que tenham informações sobre os acontecimentos em tempo real.

A pesquisa revela que grande parte das notícias está relacionada à violência doméstica que a mulher sofre, denunciando a questão de gênero que ainda predomina na sociedade. Mesmo ganhando maior discussão na mídia e dentro das casas da população brasileira, o pensamento comum demonstra a relação de poder que os sexos compõem na organização social, a chamada hierarquização dos sexos.

Ao realizar o mapeamento sobre como os sites e jornais retratam essa realidade a análise apresenta o discurso em que a mulher sofre violações dos direitos humanos a partir de uma falta de aprofundamento e abordagem do assunto nas reportagens. A veiculação dessas matérias acontece com pouca apuração sobre o caso e falta de pesquisa sobre a temática que está sendo tratada. Os meios de comunicação pouco se preocupam com os direitos civis, políticos e sociais das mulheres envolvidas.

A informação torna-se vazia quando não está embasada no conhecimento. Com um grande número de informações circulando de forma acessível, é importante ter os conhecimentos necessários para fazer a interpretação de todo o contexto e das relações que o envolvem (RADDATZ; NASI, 2017, p. 86).

O município de Santa Vitória do Palmar, região Sul do Estado, apresenta a maior porcentagem de taxa de mulheres vítimas de violência no ano de 2016. Em uma população feminina de quase 12 mil, em 2018 foram 147 denúncias envolvendo questões de violência na Lei Maria da Penha. Para a análise, foram escolhidos três veículos de diferentes portes que noticia- 
ram o mesmo ocorrido em seus respectivos sites: no dia 18 de maio de 2018, sexta-feira, uma mulher havia sido assassinada naquela manhã pelo seu companheiro que logo após cometeu suicídio.

Conforme os horários disponibilizados pelos veículos, o primeiro a divulgar informações foi o jornal Diário Popular de Pelotas - RS. Intitulado de o "jornal mais antigo do Rio Grande do Sul", liberou às $11 \mathrm{~h} 48 \mathrm{~min}$ uma notícia pequena sobre o fato, apenas com informações e uma fala sobre a fonte que encontrou o corpo da vítima. O maior portal de notícias do Rio Grande do Sul, que integra o jornal Zero Hora e a rádio Gaúcha, a Gaúcha ZH fez a postagem da notícia às $12 \mathrm{~h} 51 \mathrm{~min}$ com apenas uma nota de cinco linhas e sem detalhamento do que aconteceu. O site ainda avisa no final da notícia que "a Polícia Civil vai investigar as causas do crime", mas não complementa com outras notas em relação ao fato. No blog de notícias Evaldo Gomes, onde são veiculadas notícias da cidade de Canguçu e de toda a região sul do RS, a publicação do fato também é escassa de dados e de aprofundamento.

Esse pequeno mapeamento revela a importância de o Jornalismo preocupar-se com parâmetros éticos observando a sua linguagem e abordagem para não violar os direitos humanos, evitando falas sensacionalistas, carência da pesquisa, primando pela apuração sobre o tema. Cabe aqui também ressaltar que a própria condição do fazer jornalístico se transformou com o advento da Web, pois o uso da Internet modificou a prática dos jornalistas de averiguar as falas de suas fontes, levando muitas vezes à replicação de notícias, o que mostra a preponderância da agilidade sobre a qualidade. Há uma briga por notícias quentes, corrompendo o princípio da importância que deve ser dada ao modo como é retratada a situação, guiando-se pela ideia de que a velocidade da circulação de informações é o que define o número de acessos.

Assim, tornou-se cada vez mais importante a dedicação a buscar informações, apurar fatos, ouvir diferentes atores sociais sobre distintas e infinitas produções de conhecimento, de fatos e de poder que os embalam, colocando, idealmente, à disposição do público, determinados acontecimentos que terão relevância na vida das pessoas e que precisam, de forma diversificada, plural e precisa, estarem no dia-a-dia das pessoas, para que estas possam exercer de forma mais consciente e clara a liberdade de escolha (KARAM; CHRISTOFOLETTI, 2011, p. 80).

O Jornalismo é formado por valores, esses incluem a ética, a notícia, a verdade e o mais presente deles, o imediatismo. Para Traquina (2005, p. 37), “o fator tempo condiciona todo o processo de produção das notícias, porque o jornalismo é marcado por horas de fechamento", a pressa pela publicação torna mais intensa essa relação do jornalista com seus valores profissionais.

Essa velocidade altera muito o formato e a maneira com que as notícias são divulgadas. Mesmo que elas não estejam completas ou totalmente apuradas são publicadas e posteriormente feitas as alterações, se necessário. Essa "nova" narrativa jornalística muitas vezes fere os princípios dos direitos humanos, uma vez que a falta de profundidade com que esses profissionais abordam assuntos específicos reflete em uma sociedade cada vez menos preparada para discussões acerca do tema. 
O Jornalismo, a partir da perspectiva de seu viés social, precisa contribuir para modificar a maneira como a mulher é representada na mídia. É mais importante analisar o contexto histórico e social em que esses fatos estão inseridos do que apenas divulgá-los. O discurso social sobre a inferioridade feminina tem reflexos tanto na sociedade como nos relacionamentos afetivos.

\section{CONSIDERAÇÕES FINAIS}

A pesquisa realizada aponta para a vulnerabilidade e a fragilidade da mulher, pela forma como ela é representada na mídia, geralmente ligada a situações de violência, que corroboram também a imagem de uma fronteira violenta. Visto de modo simplista poder-se-ia afirmar que tal violência contra a mulher é produto do meio, mas a pesquisa também indica que mesmo cidades como Santa Vitória do Palmar, com cerca de 30 mil habitantes, portanto um município pequeno, também está exposto à situação de violência contra as mulheres em níveis altos, considerando as ações impetradas com o recurso da Lei Maria da Penha, conforme o quadro de monitoramento publicado pela Secretaria da Segurança Pública sobre os municípios gaúchos.

Não se quer afirmar que a mídia é a responsável pela incitação à violência, pois as razões para isso são provenientes de um conjunto de outros elementos históricos e sociais, que não constituem o foco deste estudo. É importante salientar, porém, que a mídia tem um papel crucial na formação dos pontos de vista e na criação do imaginário e reside neste ponto a sua cota de responsabilidade quanto àquilo que está reproduzindo sobre gênero e fronteira e até que ponto não estaria ferindo os princípios dos direitos humanos.A era dos direitos corresponde a um período da História em que emergem em todas as instâncias de comunicação discursos pela proteção dos direitos humanos, na medida em que se reconhecem os níveis de desigualdade social entre milhões de seres humanos pelo mundo. Ao mesmo tempo floresce também a consciência de que existe uma hegemonia de classes econômicas e que isso influi diretamente na violação desses direitos. Há, portanto, um paradoxo a ser resolvido.

A cidadania é o lugar de fala para vigiar e interceder de forma ininterrupta nesse processo, não só pelo discurso, mas por ações no espaço público. Se a mídia reúne todas as características que se aproximam do cidadão, eticamente pode também exercer a cidadania e ser um elemento articulador ativo e participante por meio de sua comunicação nesse espaço público. Seu diferencial é a possibilidade de ocupar um lugar privilegiado de fala, pois se dirige a um grande contingente de pessoas e ao mesmo tempo pode manifestar-se por elas, pode indagar, investigar, fiscalizar, sugerir, informar, comparar, analisar e interpretar uma realidade, enfim, formar pontos de vista e questionar opiniões. Assim, principalmente os meios que recebem concessão pública para funcionar, deveriam ser cobrados para que de fato representem as múltiplas vozes, não podendo fugir do compromisso com a cidadania e a defesa dos direitos humanos.A mídia como espaço público é o lugar também de fala do cidadão que hoje quer participar do processo de comunicação, sentindo-se coautor e plenamente envolvido no sistema, considerando que há várias formas de participação, potencializadas pelas ferramentas de Internet. Ao perceber que a problemática de seu interesse está presente na mídia, o cidadão sente-se incluído e contemplado nas suas expectativas, o que gera empoderamento do indivíduo e capitaliza a audiência. Isto Ihe dá mais autonomia para discutir, avaliar, tomar 
decisões, qualificando inclusive a própria participação. Esta proximidade e o sentimento de fazer parte do processo criam vínculos entre a mídia e os cidadãos e estabelecem uma comunicação dialógica, capaz de fazer ambos olharem para dentro de si mesmos, reconhecendo seus iguais e diferentes, ampliando a sua visão do humano.

Os direitos humanos, portanto, precisam fazer parte da pauta da mídia, o espaço público por excelência da comunicação pelo e para o seu entorno, sem perder de vista a problemática da humanidade.

\section{REFERÊNCIAS}

ARENDT, Hannah. A condição humana. Rio de Janeiro: Forense Universitária, 1958-2004.

BEDIN, Gilmar Antonio; GRANDO, Juliana Bedin. A universalidade dos Direitos Humanos e seu percurso no século XX. In: SILVEIRA, Vladimir Oliveira da; LOPES Ana Maria D’Ávila; SPOSATO, Karyna Batista. (org.). Direito internacional dos direitos humanos [Recurso eletrônico on-line]. Florianópolis: Conpedi; UFS, 2015.

BEDIN, Gilmar Antonio. Os direitos do homem e o neoliberalismo. 3. ed. rev. e ampl. Ijuí: Ed. Unijuí, 2002.

BOBBIO, Norberto. A era dos Direitos. Campus: Rio de Janeiro, 1992.

BOURDIEU, Pierre. A dominação masculina: a condição feminina e a violência simbólica; tradução Maria Helena Kühner. 1. ed. Rio de Janeiro: BestBolso, 2014.

BRASIL. Constituição de 1988. 1988. Disponível em: http://www2.camara.leg.br/atividade-legislativa/legislacao/ Constituicoes_Brasileiras/constituicao1988.html/Constituiode1988.pdf. Acesso em: mar. 2018.

CANCLINI, Néstor Garcia. Culturas híbridas: estratégias para entrar e sair da modernidade. São Paulo: Editora da Universidade de São Paulo, 1997.

COLLING, Ana Maria. Tempos diferentes, discursos iguais: a construção histórica do corpo feminino. Dourados, MS: Ed. UFGD, 2014.

DIÁRIO POPULAR. Mulher é morta pelo companheiro em Santa Vitória do Palmar. Disponível em: http://www. diariopopular.com.br/index.php?n_sistema=3056\&id_noticia=MTMyNjE2\&id_area=Nw==. Acesso em: 23 maio 2018.

GAÚCHA ZH. Mulher é morta pelo marido dentro de casa no sul do RS. Disponível em: https://gauchazh.clicrbs. com.br/seguranca/noticia/2018/05/mulher-e-morta-pelo-marido-dentro-de-casa-no-sul-do-rs-cjhc542t509fg01qoxxx1bj71.html. Acesso em: 23 maio 2018.

IPHAN. Instituto do Patrimônio Histórico e Artístico Nacional (Brasil). Ponte Internacional Barão de Mauá: dossiê de candidatura: Patrimônio Cultural do Mercosul - PCM = Puente Internacional Barón de Mauá : dossier de candidatura : Patrimonio Cultural del Mercosul - PCM; Instituto do Patrimônio Histórico e Artístico Nacional. Brasília-DF: IPHAN, 2015.

JODELET, Denise. Representações sociais: um domínio em expansão. In: JODELET, Denise (org.). As representações sociais. Rio de Janeiro: Eduerj, 2002.

KARAM, Francisco José Castilhos; CHRISTOFOLETTI, Rogério (org.). Configurações políticas: fundamentos jornalísticos para novos cenários éticos da informação. In: SILVA, Gislene (org.). Jornalismo contemporâneo: figurações, impasses e perspectivas. Salvador: Edufba, 2011. Disponível em: http://www.sisbin.ufop.br/novoportal/ wp-content/uploads/2015/03/JORNALISMO-CONTEMPORANEO.pdf. Acesso em: 22 maio 2018.

LAFER, Celso. Hannah Arendt: pensamento, persuasão e poder. São Paulo: Paz e Terra, 2003.

MÜLLER, Karla. Mídia local fronteiriça: do impresso ao on-line. In: RADDATZ, Vera Lucia Spacil; MÜLLER, Karla Maria (org.). Comunicação, cultura e fronteiras. ljuí: Ed. Unijuí, 2015.

NOTÍCIAS EVALDO GOMES. Homem mata mulher e depois se suicida em Santa Vitória do Palmar. Disponível em: https://eg-leal.blogspot.com/2018/05/homem-mata-mulher-e-depois-se-suicida.html. Acesso em: 23 maio 2018.

OLIVEIRA, Tito Carlos Machado. Fronteiras de Comunicação: movimentos, sentidos e semblantes. In: RADDATZ, Vera Lucia Spacil; MÜLLER, Karla Maria. Comunicação, cultura e fronteiras. Ijuí: Ed. Unijuí, 2015.

OTA, Daniela. Radiojornalismo na fronteira: especificidades na produção e disseminação do conteúdo jornalístico. In: RADDATZ, Vera Lucia Spacil; MÜLLER, Karla Maria. Comunicação, cultura e fronteiras. ljuí: Ed. Unijuí, 2015. PESAVENTO, Sandra Jatahy. Além das fronteiras. In: MARTINS, Maria Helena (org.). Fronteiras culturais. Cotia, SP: Ateliê Editorial, 2002. 
RADDATZ, Vera Lucia Spacil; NASI, Lara. O jornalismo como campo mediador dos direitos humanos. Comunicação \& Sociedade, São Bernardo do Campo, v. 39, n. 2, p. 79-102, maio/ago. 2017.

PREFEITURA DE ACEGUÁ. Histórico. Disponível em: http://www.acegua.rs.gov.br. Acesso em: 23 maio 2018.

SCOTT, Joan. La citoyenne paradoxale: lês féministes françaises et lês droits de I 'homme. Paris: Editions Albin Michel, 1998.

SSP. Secretaria de Segurança Pública. Departamento de Integração, Planejamento e Política de Segurança. Observatório Estadual de Segurança Pública. Monitoramento dos indicadores de violência contra as mulheres $e$ meninas. Disponível em: http://www.ssp.rs.gov.br/upload/arquivos/201805/18130728-indicadores-criminais-geral-2018.xlsx. Acesso em: mar. 2018.

TRAQUINA, Nelson. Teorias do jornalismo: por que as notícias são como são. Florianópolis: Insular, 2005. 1 v. 